\title{
Properties of Ribosomes from Acanthamoeba castellanii
}

\author{
By J. H. PARISH AND L. HALL \\ Department of Biochemistry, University of Leeds, \\ 9 Hyde Terrace, Leeds $L S_{2}{ }_{9} L S$ \\ (Received I3 June 1972; revised 5 July 1972)
}

\begin{abstract}
SUMMARY
Polyribosomes were isolated from vegetative cells of Acanthamoeba castellanii NEFF. Ribosomes, of sedimentation coefficient $97 \mathrm{~S}$, were isolated from vegetative cells and cysts. Both polyribosomes and ribosomes dissociated in $0.3 \mathrm{M}-\mathrm{KCl}$ to particles of sedimentation coefficients 66,53 and $40 \mathrm{~S}$, and a slowly sedimenting particle whose sedimentation coefficient was not measured. RNA was extracted from the particles and fractionated. The $53 \mathrm{~S}$ and $40 \mathrm{~S}$ particles are the ribosomal subunits; the 97 and $66 \mathrm{~S}$ particles contained RNA characteristic of both subunits.
\end{abstract}

\section{INTRODUCTION}

Acanthamoeba castellanii* is a Hartmanellid amoeba particularly suited to metabolic and structural studies as it can be readily grown in axenic culture. The properties of the ribosomes of this organism are of particular interest in the light of its unusual rRNA. The RNA ( 8 S RNA) from the smaller ribosomal subunit is anomalously large (mol.wt $0.9 \times 10^{6}$; Loening, 1968a) and the large RNA (26 S RNA) molecule from the larger ribosomal subunit contains in vivo a single-strand break, with the result that, upon denaturation, two RNA species are derived from it (Stevens \& Pachler, 1972).

These properties, unusual among eukaryotic organisms, may be reflected in anomalous properties of the ribosome. Stevens \& Pachler (1972) described a method for obtaining a ribosomal pellet from the vegetative cells but presented no data on the properties of the ribosomes. Changes in ribosomal structure might also be associated with the morphogenetic cycle of the amoeba.

\section{METHODS}

Chemicals. Mycological Peptone was obtained from Oxoid Ltd, London, Tris base from Sigma Chemical Co, St Louis, Missouri, U.S.A., puromycin hydrochloride from the Nutritional Biochemicals Corporation, Cleveland, Ohio, U.S.A., and sodium tri isopropylnaphthalene sulphonate from Kodak Ltd, London. Nonidet $\mathrm{P}_{40}$ was a gift from Shell Chemicals Ltd, London. All other chemicals were obtained from British Drug Houses Ltd, Poole, Dorset, and were of AnalaR grade wherever possible. Acrylamide and methylene bis acrylamide (used for making polyacrylamide gels for electrophoresis) were recrystallized by the methods of Loening (1968b).

Growth of amoebae. Acanthamoeba castellanii NEFF was kindly supplied by Dr U. E. Loening of the Department of Zoology, University of Edinburgh. The organism was maintained by serial transfer in small flasks of $4 \%(\mathrm{w} / \mathrm{v})$ Mycological Peptone at room temperature. For growth, a sample ( $10 \mathrm{ml}$ ) of a stock culture was added aseptically to $250 \mathrm{ml}$ of $4 \%$ Mycological Peptone, supplemented with $0.9 \%(\mathrm{w} / \mathrm{v})$ maltose, in a I l flask

* Referred to the genus Hartmanella in some earlier literature. 
and was swirled at 28 to $30{ }^{\circ} \mathrm{C}$. The progress of these cultures was followed by examining samples under the phase-contrast microscope. Vegetative cells, containing a few multinucleate forms (James \& Byers, 1967) were harvested after 4 to 7 days. Cysts were harvested from older cultures ( 14 to 20 days). Both vegetative cells and cysts were harvested by centrifugation ( $2400 \mathrm{rev} . / \mathrm{min}$ in the MSE Mistral centrifuge for $40 \mathrm{~min}$ at $4{ }^{\circ} \mathrm{C}$ ).

Isolation of ribosomes and polyribosomes. Ribosome pellets (from either vegetative cells or cysts) were prepared by freezing the cells at $-20^{\circ} \mathrm{C}$ and crushing them in the Hughes Press. This preparation was suspended at $0{ }^{\circ} \mathrm{C}$ in an equal volume of $25 \mathrm{~mm}-\mathrm{KCl}, 5-\mathrm{mm}-\mathrm{Mg}$ $(\mathrm{OAc})_{2}, 50 \mathrm{mM}$-tris- $\mathrm{HCl}, \mathrm{pH} 7 \cdot 8$, and centrifuged at $1000 \mathrm{~g}$ for $20 \mathrm{~min}$ at $4{ }^{\circ} \mathrm{C}$ to remove nuclei, intact cells and debris. Nonidet $\mathrm{P}_{40}$ (a non-ionic detergent) was added to the supernatant fluid to $\mathrm{I} \%(\mathrm{v} / \mathrm{v})$ and the suspension was left at $0{ }^{\circ} \mathrm{C}$ for $\mathrm{I} 5 \mathrm{~min}$. The suspension was layered over I. $5 \mathrm{M}$-sucrose (in the same buffer as above) and centrifuged at $78000 \mathrm{~g}$ for $15 \mathrm{~h}$ at $4{ }^{\circ} \mathrm{C}$. The supernatant layers were removed. In this procedure, it is important to suck the very top of the liquid off first (most conveniently by using a Pasteur pipette attached to a water pump) as lipid, presumed to be derived from cytoplasmic vacuoles, is emulsified by the Nonidet and forms a sticky white layer at the top of the tube.

To obtain polyribosomes, vegetative cells of Acanthamoeba castellanii were suspended in 2 vol. buffer (as above) containing $0.15 \mathrm{M}$-sucrose and homogenized in a Teflon-in-glass homogenizer with a rotating pestle at 0 to $4{ }^{\circ} \mathrm{C}$. The $1000 \mathrm{~g}$ supernatant from this homogenate was obtained, treated with Nonidet and layered over I.5 M-sucrose as described above. It was centrifuged for $3 \mathrm{~h}$ at $165000 \mathrm{~g}$ at $4{ }^{\circ} \mathrm{C}$. The supernatant was obtained from the pellets as described above.

Rat liver polyribosomes were isolated by the 'C-ribosome' procedure of Wettstein, Staehelin \& Noll (1963).

Fractionation of ribosomes. Ribosomes were fractionated by sucrose-gradient centrifugation. Details of buffers and conditions appear in the legends to the appropriate Figures. Sucrose gradients were monitored by pumping them through a flow-through cuvette of the Gilford/Unicam 2000 continuous-recording spectrophotometer. For certain experiments the ribosomes were isolated from such gradients by collecting fractions on ice, diluting with buffer (lacking sucrose) and centrifuging at $\mathrm{I} 65000 \mathrm{~g}$ for $\mathrm{I} 2 \mathrm{~h}$.

Isolation of RNA. RNA was isolated from vegetative cells of Acanthamoeba castellanii by the method of Parish \& Kirby (1966) with the modification that a third deproteinization was performed. The upper phase from the second deproteinization was re-extracted with $0.5 \mathrm{vol}$ of the 'phenol mixture' employed in this procedure. RNA of high molecular weight was precipitated with $4 \mathrm{M}-\mathrm{NaCl}$ (Parish \& Kirby, I966). RNA was isolated from ribosome pellets by the same procedure except that purified tRNA (from Escherichia coli) was added to the suspension as co-precipitant and the precipitation with $4 \mathrm{M}-\mathrm{NaCl}$ and subsequent washings with $3 \mathrm{M}-\mathrm{NaOAc}$, which remove DNA from RNA preparations, were omitted.

Sedimentation coefficients of ribosomes and subunits. Suspensions of ribosomes in buffer (see Table I for details) were centrifuged in a quartz-window cell (Al centrepiece) of the An-D rotor of a Beckman model E ultracentrifuge fitted with Schlieren and single-beam u.v. optics. All runs were performed at $20^{\circ} \mathrm{C}$ at either 42040 or $43500 \mathrm{rev}$./min. For measurements of sedimentation coefficients, nine or ten photographs were taken at 2 min intervals ( $\mathrm{I} O \mathrm{~s}$ exposure) in the u.v. system ribosome suspensions of concentrations corresponding to $E_{260} \mathrm{I} \mathrm{cm}$ in the range $\mathrm{r} \cdot 0$ to $5^{\circ} \mathrm{O}$. The photographs were scanned in the Joyce Loebel Chromoscan and $s_{20}$ values for the boundaries and extrapolated $s_{20}^{0}$ values were calculated by conventional graphical methods. 


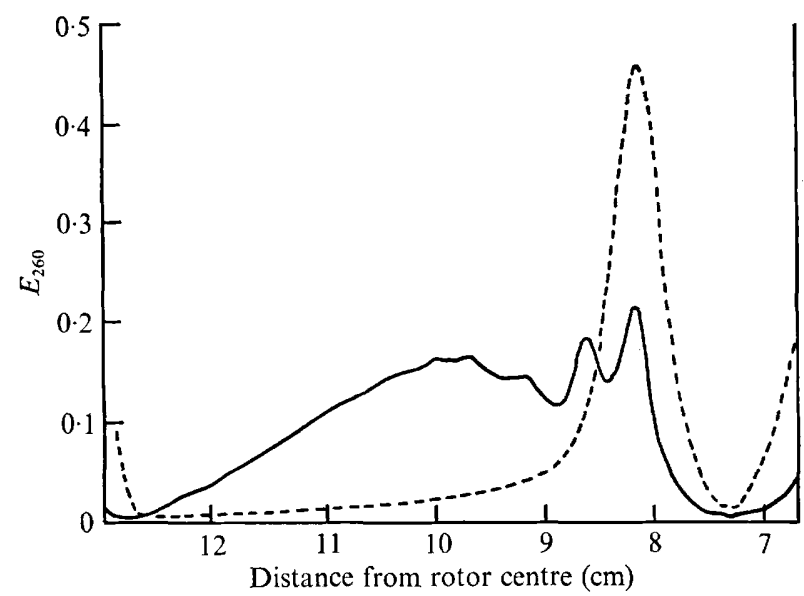

Fig. 1. Polyribosomes from vegetative cells of Acanthamoeba castellanii. Polyribosomes were suspended in $25 \mathrm{~mm}-\mathrm{KCl}, 5 \mathrm{~mm}-\mathrm{Mg}(\mathrm{OAc})_{2}, 50 \mathrm{mM}$-tris- $\mathrm{HCl}, \mathrm{pH} 7 \cdot 8$, and layered over linear gradients of ro to $30 \%(\mathrm{w} / \mathrm{v})$ sucrose in the same buffer in tubes for the SW $25 . \mathrm{I}$ rotor of the Beckman model L ultracentrifuge. Centrifugation was at $24500 \mathrm{rev}$./min at $4{ }^{\circ} \mathrm{C}$ for $1.6 \mathrm{~h}$. The two traces show parallel gradients of identical amounts of the same suspension except that one (- -) had been incubated for $5 \mathrm{~min}$ at $20{ }^{\circ} \mathrm{C}$ with $7.5 \mu \mathrm{g} / \mathrm{ml}$ bovine pancreatic ribonuclease; the other $(\longrightarrow$ ) is the control.

Fractionation of $R N A$. RNA was fractionated by electrophoresis at $4{ }^{\circ} \mathrm{C}, 8 \mathrm{~V} / \mathrm{cm}$ for $2 \mathrm{~h}$ in $2.5 \%$ polyacrylamide gels using the procedures of Loening ( $1968 \mathrm{~b}$ ) with the following minor modifications. The gels and running buffer contained $0.5 \%(\mathrm{w} / \mathrm{v})$ sodium tri isopropylnapththalene sulphonate in place of the dodecyl sulphate used by Loening. The gels were stained by immersion in $0.5 \%(\mathrm{w} / \mathrm{v})$ toluidine blue in $40 \%(\mathrm{v} / \mathrm{v})$ aqueous 2-ethoxyethanol for $\mathrm{I} h$, and destained in $40 \%$ 2-ethoxyethanol for about $30 \mathrm{~h}$. They were scanned in the Joyce Loebel Chromoscan.

\section{RESULTS}

\section{Polyribosomes, ribosomes and their dissociation}

A very low yield of ribonucleoprotein was obtained from a 'post-mitochondrial supernatant' prepared as for the isolation of rat-liver microsomes and polyribosomes (Wettstein, Staehelin \& Noll, 1963) and consequently the method described here, employing a 'post-nuclear supernatant', was used for all preparations. Sucrose-gradient analysis of the particles obtained by gentle breakage of vegetative cells produced a typical polyribosome profile. The nature of the fast sedimenting particles and the identity of the monoribosome peak were confirmed by incubation with a small amount of ribonuclease, which produced a single monoribosome peak (Fig. I).

Treatment of polyribosomes with $0.3 \mathrm{M}-\mathrm{KCl}$ produced an unexpected dissociation to produce a single slowly sedimenting peak in sucrose gradients, such as those in Fig. I. Rat-liver polyribosomes dissociate into subunits, under these ionic conditions, only after treatment with puromycin (Blobel \& Sabatini, 1971). Puromycin had no apparent effect on the dissociation of Acanthamoeba castellanii polyribosomes, which did not require such treatment.

Dissociation to particles that constitute this slowly sedimenting peak likewise occurred with a monoribosome preparation, obtained by crushing frozen cells. As crushing was 


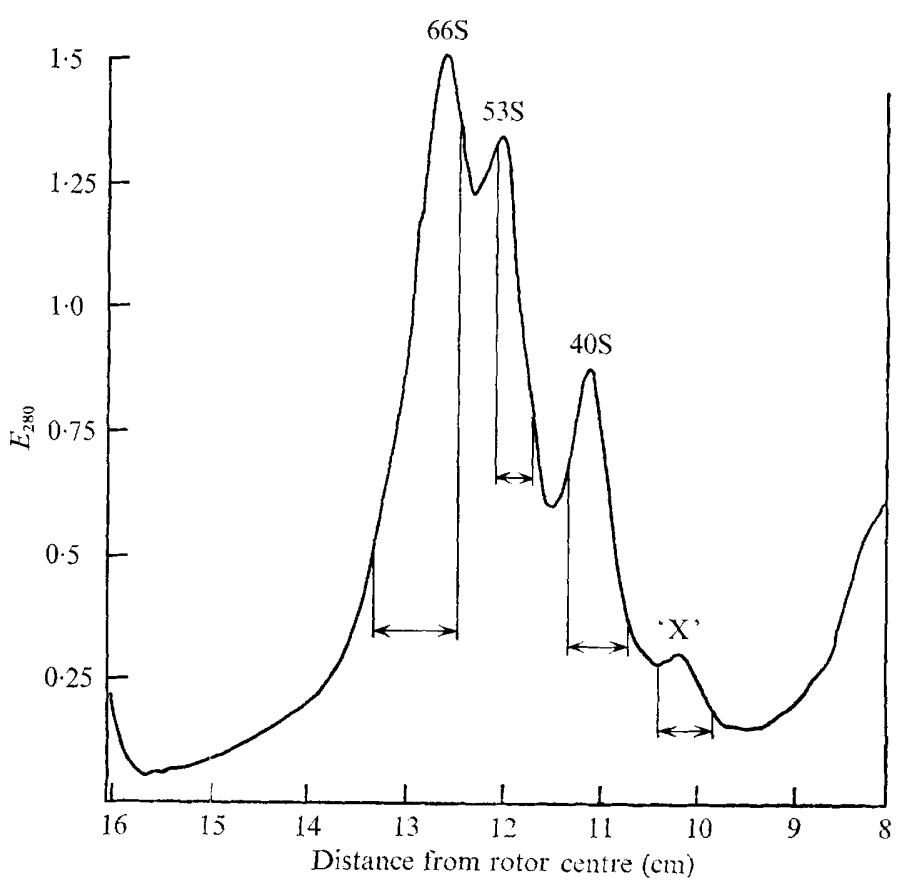

Fig. 2. Preparative fractionation of particles derived from vegetative-cell ribosomes of Acanthamoeba castellanii in strong $\mathrm{KCl}$. A linear gradient of $\mathrm{I} 5$ to $35 \%(\mathrm{w} / \mathrm{v})$ sucrose in $0.3 \mathrm{M}-\mathrm{KCl}$, $5 \mathrm{mM}^{-\mathrm{MgCl}_{2}}$, $10 \mathrm{~mm}$-tris- $\mathrm{HCl}, \mathrm{pH} 7 \cdot 6,6 \mathrm{~mm}$-2-mercaptoethanol was established in a $35 \mathrm{ml}$ tube of the SW 27 rotor for the Beckman model L 2-65 B ultracentrifuge. Ribosomes were suspended in $0.5 \mathrm{M}-\mathrm{KCl}, 5 \mathrm{~mm}-\mathrm{MgCl}_{2}$, Io mM-tris- $\mathrm{HCl}, \mathrm{pH} \mathrm{7.6,6} \mathrm{mM-2-mercaptoethanol.} \mathrm{Centrifugation} \mathrm{was}$ for $15 \mathrm{~h}$ at $19500 \mathrm{rev}$. $/ \mathrm{min}$ and $4{ }^{\circ} \mathrm{C}$. Fractions indicated were collected and pelleted (see Methods). Fractions from five such gradients were pooled for subsequent experiments. $X$ is a slowly sedimenting zone referred to in the text.

Table I. Sedimentation coefficients ( $s_{20}^{0}$ in Svedberg units) for boundaries due to ribosomal particles derived from Acanthamoeba castellanii

Buffers all contained, in addition to $\mathrm{KCl}, 5 \mathrm{~mm}-\mathrm{MgCl}_{2}$, Io mM-tris- $\mathrm{HCl}$, $\mathrm{pH} 7 \cdot 6$. Numbers in parentheses refer to minor boundaries (less than $10 \%$ of total).

$\begin{array}{lrcccc}\text { Cell type } & \mathrm{KCl} & & & & \\ \text { Vegetative } & 25 \mathrm{mM} & 97 \cdot 8 & - & (54 \cdot 9) & (40 \cdot 8) \\ \text { Vegetative } & 300 \mathrm{mM} & - & (67 \cdot 2) & 49 \cdot 1 & 40 \cdot 8 \\ \text { Cysts } & 25 \mathrm{mM} & 96 \cdot 5 & - & (52 \cdot 9) & (39 \cdot 6) \\ \text { Cysts } & 300 \mathrm{mM} & - & (65 \cdot 8) & 53 \cdot \mathbf{I} & 38 \cdot 9\end{array}$

the only procedure by which we could break open Acanthamoeba castellanii cysts, we used such preparations for further studies on ribosomes from both cell types.

In sucrose gradients the amoeba ribosomes sedimented faster than $80 \mathrm{~S}$ monoribosomes of a rat-liver 'C-ribosome preparation'.

The sedimentation coefficients of particles in ribosome preparations from Acanthamoeba castellanii are summarized in Table I. These particles will be referred to as 97, 66, 53 and $40 \mathrm{~S}$ particles.

Isolation of ribosomal particles and $R N A$. The particles identified as boundaries in the analytical centrifuge were separated by sucrose-gradient centrifugation. A preparative 


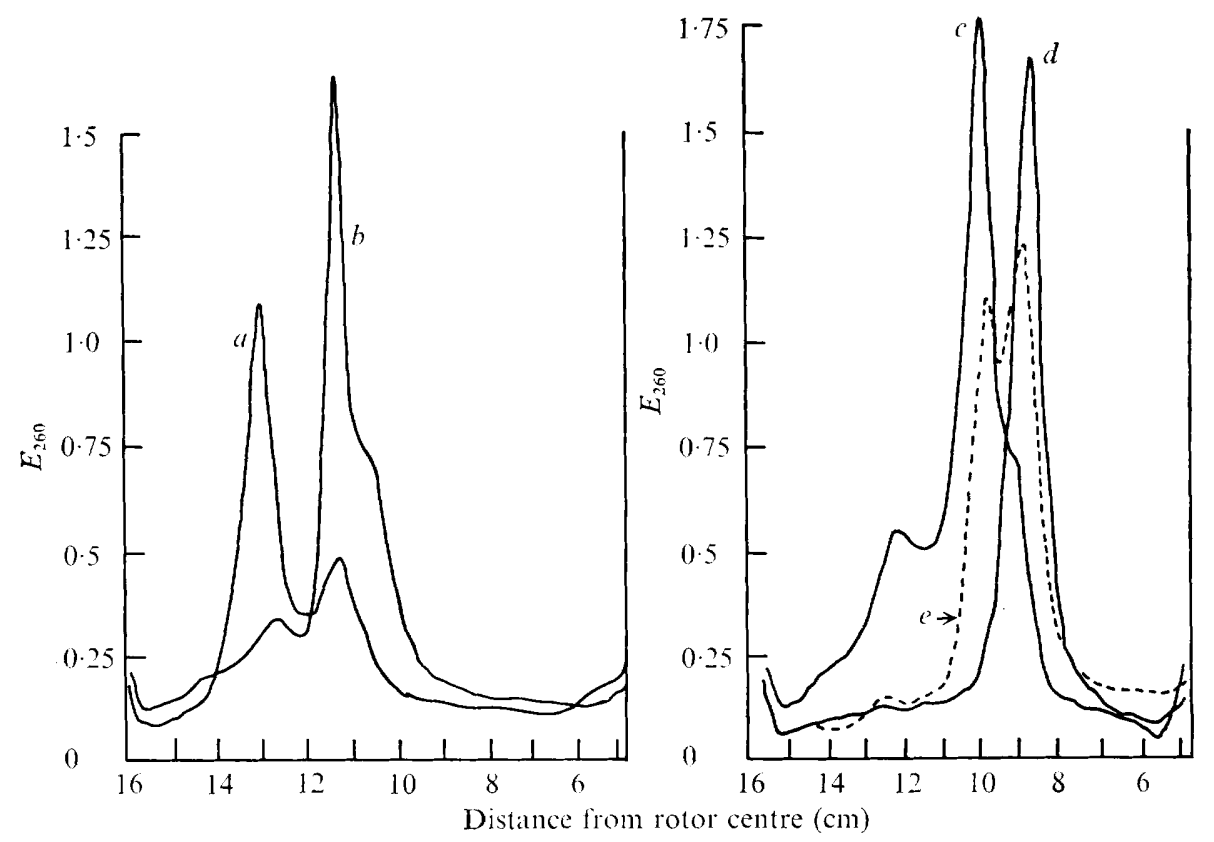

Fig. 3. Various ribosomal particles from Acanthamoeba castellanii. Linear gradients of sucrose $(15-35 \%, w / v)$ in $0.1 \mathrm{M}-\mathrm{NH}_{4} \mathrm{Cl}, 5 \mathrm{~mm}-\mathrm{Mg}(\mathrm{OAc})_{2}, 20 \mathrm{~mm}$-tris- $\mathrm{HCl}, \mathrm{pH} 7.6$, were established in $17 \mathrm{ml}$ tubes of the SW 27 rotor for the Beckman model L 2-65 B ultracentrifuge. Ribosomes, were suspended in $0.15 \mathrm{M}-\mathrm{NH}_{4} \mathrm{Cl}, 5 \mathrm{mM}-\mathrm{Mg}(\mathrm{OAc})_{3}, 20 \mathrm{mM}$-tris- $\mathrm{HCl}, \mathrm{pH} 7.6$. Samples $(0.4 \mathrm{ml})$ were layered over the gradients and centrifugation was for $15 \mathrm{~h}$ at $19500 \mathrm{rev} . / \mathrm{min}$ and $4{ }^{\circ} \mathrm{C}$. $a$, Unfractionated ribosomes; $b, 66 \mathrm{~S}$ particles (from Fig. 4); $c, 53 \mathrm{~S}$ particles (from Fig. 4); $d, 40 \mathrm{~S}$ particles (from Fig. 4); $e$, a mixture of 53 and $40 \mathrm{~S}$ particles (in the ratio of $6 \cdot 7: 5.5$ ) incubated at $30{ }^{\circ} \mathrm{C}$ for $20 \mathrm{~min}$ prior to layering on the gradient.

fractionation of particles in strong $\mathrm{KCl}$ is illustrated in Fig. 2. Comparison with Table I demonstrates two points of difference. The $66 \mathrm{~S}$ particle, present as a minor boundary in the analytical centrifuge, was present in relatively large amounts in the sucrose gradient. We ascribe this difference to the lower temperature $\left(4{ }^{\circ} \mathrm{C}\right.$ as opposed to $\left.20^{\circ} \mathrm{C}\right)$ in the preparative centrifuge. The second point of difference is that a fourth zone ( $X$ in Fig. 2) was seen, which being absent in the analytical centrifuge, could not be assigned a sedimentation coefficient.

Density-gradient centrifugation of various ribonucleoprotein particles from Acanthamoeba castellanii run in the buffer in which mouse-liver ribosomal subunits re-associate best (Falvey \& Staehelin, I 970) showed no significant re-association of $53 \mathrm{~S}$ and $45 \mathrm{~S}$ particles (Fig. $3 c, d, e$ ).

Electrophoresis of RNA (Fig. 4) isolated from cells and from ribosomal particles from the sucrose gradients (Fig. 2,3) showed that the $40 \mathrm{~S}$ particle contained I8 S RNA and was therefore the smaller ribosomal subunit. The $53 \mathrm{~S}$ particle contained $26 \mathrm{~S}$ and i $8 \mathrm{~S}$ RNA. With the exception of $X$, rRNA from all the ribosomal particles was degraded by ribonuclease present in the ribosomes. Some or all of this nuclease activity could be due to the enzyme that introduces the 'hidden break' in the $26 \mathrm{~S}$ RNA. RNA isolated from unfractionated ribosomal pellets showed no degradation (Stevens \& Pachler, 1972). The inevitably longer times between isolation and deproteinization of the ribosomes in the present work presumably exposed the RNA to nuclease activity. 

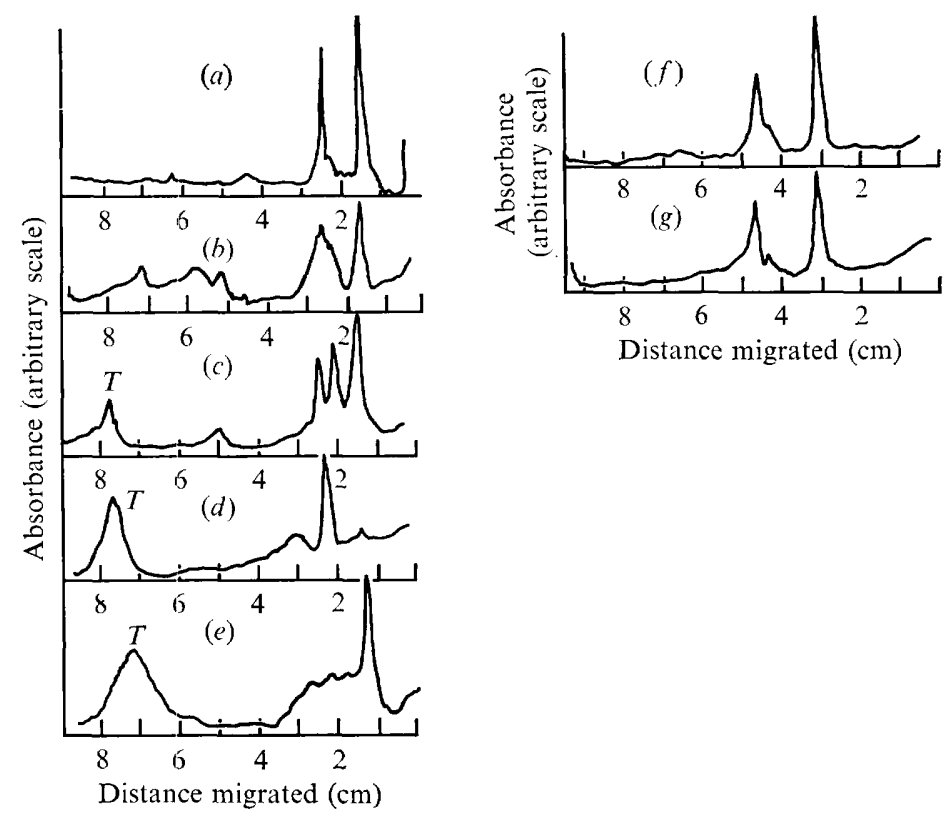

Fig. 4. Fractionation of rRNA from Acanthamoeba castellanii by gel electrophoresis (details in Methods). $T=$ Escherichia coli tRNA. $(a)$ and $(f)$ Whole-cell RNA; $(b)$ RNA from the 97 S particle; (c) RNA from the $66 \mathrm{~S}$ particle; $(d)$ RNA from the $53 \mathrm{~S}$ particle; $(e)$ RNA from the $40 \mathrm{~S}$ particle; $(g)$ RNA from $X$. Gels $(a)$ to $(e)$ were run in parallel in one experiment; $(f)$ and $(g)$ were run in parallel in a separate experiment.

\section{DISCUSSION}

The dissociation of ribosomes and polyribosomes from Acanthamoeba castellanii is so unusual that it is not yet possible to differentiate between ribosomes of the vegetative cells and in the cysts. Studies on protein biosynthesis in vitro are clearly necessary to determine the ribosome cycle in this organism. Similarly, no role can yet be assigned to zone $X$. It is possible that this is an artificial degradation product. We regard this as unlikely as degradation of ribosomes during their extraction is usually associated with RNA breakdown and $X$ is the only particle for which there is no such evidence (Fig. 4). Alternatively, $X$ may contain very slowly sedimenting forms of the subunits or their precursors, or even free rRNA.

Concerning the 97 and $66 \mathrm{~S}$ particles and the ribosomal subunits, a simple rationale is that the $40 \mathrm{~S}$ particle was the typical smaller subunit of eukaryotic organisms but that the $53 \mathrm{~S}$ particle underwent a conformational change during dissociation of the ribosome to produce the anomalously low sedimentation coefficient. The monoribosome apparently underwent such a conformational change in $0.3 \mathrm{M}-\mathrm{KCl}$ from a highly condensed $(97 \mathrm{~S})$ to more open (66 S) conformation before dissociating. This conformational flexibility of Acanthamoeba castellanii ribosomes may be due to a degree of freedom introduced into the quaternary structure by the discontinuity in the 26 S RNA. 


\section{REFERENCES}

Blobel, G. \& Sabatini, D. (197I). Dissociation of mammalian polyribosomes into subunits by puromycin. Proceedings of the National Academy of Sciences of the United States of America 68, 390-400.

Falvey, A. K. \& Staehelin, T. (1970). Structure and function of mammalian ribosomes. I. Isolation and characterization of active liver ribosomal subunits. Journal of Molecular Biology 53, I-19.

JAMES, T. E. \& BYERS, T. J. (1967). The induction of multinuclearity in agitated and in aging cultures of Acanthamoeba sp. Neff. Journal of Cellular Physiology 7o, 53-61.

LOENING, U. E. (1968a). Molecular weights of ribosomal RNA in relation to evolution. Journal of Molecular Biology 38, 355-365.

LoENING, U. E. (I968b). The fractionation of high molecular weight RNA. In Chromatographic and Electrophoretic Techniques, vol. 2. Zone Electrophoresis. Edited by I. Smith. London: Heinemann.

PARISH, J. H. \& KIRBY, K. S. (1966). Reagents which reduce interactions between ribosomal RNA and rapidly labelled RNA from rat liver. Biochimica et biophysica acta I29, 554-562.

STEVens, A. R. \& PAChler, E. F. (1972). Discontinuity of 26 srRNA in Acanthamoeba castellani. Journal of Molecular Biology 66, 225-237.

Wettstein, F. O., Staehelin, T. \& Noll, H. (1963). Ribosomal aggregate engaged in protein synthesis: characterization of the ergosome. Nature, London 197, 430-435. 